Assiut University web-site: www.aun.edu.eg

\title{
L-ARGININE ACCENTUATES SICKNESS BEHAVIOR INDUCED BY LIPOPOLYSACCHARIDES IN MALE ALBINO RATS
}

\author{
HAMDY M. EMBARK \\ Animal Physiology Department, Faculty of Vet. Medicine, South Valley University, Qena 83523, Egypt
}

Received: 31 December 2016; $\quad$ Accepted: 31 January 2017

\begin{abstract}
Sickness behavior is a behavioral changes occurring soon after the onset of infection, trauma, and inflammatory processes. In animals, systemic administration of lipopolysaccharide (LPS) induces a characteristic set of responses that has been termed "sickness behavior". Recent empirical results have provided an evidence that inhibition of the production of nitric oxide (NO) from L-arginine (L-Arg) by $\mathrm{N}^{\mathrm{G}}$ nitro-L-arginine methyl ester (L-NAME) accentuated LPS-induced sickness behaviors in male rats. The impact of the L-Arg on LPS-induced sickness behaviors in rats has not yet been tested. To evaluate the possible participation of L-Arg/NO pathway in LPS-induced sickness behaviors, rats were tested in the open field test using LE8811 Actimeter PanLAB device. Rats were weighed, randomly divided into 4 groups (five rats in each group), and intraperitoneally injected as follow: Control group (saline, $0.1 \mathrm{ml} / 100 \mathrm{~g}$ b.wt), LPS group (LPS, $1 \mathrm{mg} / \mathrm{kg} \mathrm{b.wt),} \mathrm{L-arginine} \mathrm{group} \mathrm{(L-Arg,} 10 \mathrm{mg} / \mathrm{kg}$ b.wt, for 7 days), and LPS+L-arginine group (L-Arg, $10 \mathrm{mg} / \mathrm{kg}$ b.wt, for 7 days then once injected with LPS, 1mg/kg). Locomotor and behavioral activity levels of the animals were evaluated to measure horizontal activity (units), vertical activity (units), stereotype (units) movements, total distance traveled $(\mathrm{cm})$, and average velocity. LPS decreased locomotor and behavioral activities but not reaching significance. In contrast, the pretreatment with L-Arg was associated with an increase in locomotor and behavioral activities but also not reaching significance. Interestingly, pretreatment with L-Arg of LPS-treated rats accentuated locomotor and behavioral changes induced by LPS. In conclusion, the results of this study support the hypothesized relationship between NO synthesis and modulation of sickness behaviors and suggest that NO may has a dual role in the modulation of sickness behaviors depending on intensity and stage of inflammation.
\end{abstract}

Key words: lipopolysaccharide, nitric oxide, L-arginine, rats.

\section{INTRODUCTION}

The term "sickness behaviour" (abnormal illness behavior) is an organized and systematic strategy of the organism(s) to fight off the infection (Dantzer et al., 2001). This strategy is often triggered by the proinflammatory cytokines that are produced by activated neutrophils and monocytes/ macrophages in contact with invading microbes (Hart, 1988; Kent et al., 1992). These cytokines include mainly interleukin 1 (IL- $1 \alpha$ and IL-1 $\beta$ ), interleukin 1 (IL-6) and tumour necrosis factor (TNF) (formerly known as TNF-alpha or cachectin) (Larson and Dunn, 2001).

Increased proinflammatory cytokines cause a coordinated set of adaptive psychological changes such as depression and anhedonia, which are

Corresponding author: HAMDY M. EMBARK

E-mail address: h.embark@vet.svu.edu.eg; atutohm@yahoo.com Present address: Animal Physiology Department, Faculty of Vet. Medicine, South Valley University, Qena 83523, Egypt. recognized as emotional aspects of sickness behavior, in patients with infection and cancer (Dantzer et al., 2008; DellaGioia and Hannestad, 2010). Behavioral effects have been well-studied in animal models of inflammation induced by the bacterial endotoxin, lipopolysaccharide (LPS) (Frenois et al., 2007; de Paiva et al., 2010).

LPS is the major component of the outer membrane of Gram-negative bacteria, contributing greatly to innate immune responses from normal animal immune systems (Miyake, 2003; Kirsten et al., 2013). LPS is considered a potent sickness behavior and proinflammatory cytokine-inducer (Bluthe et al., 1994; Aubert, 1999).

LPS-induced behavioral changes can be divided into transient changes such as decreases in locomotor activity and food intake, and persistent changes such as depressive-like behavior and exploratory behavior deficit (Frenois et al., 2007; Haba et al, 2012).

L-arginine (L-Arg) is an important natural amino acid in the body that is used in nutritional 
supplements (Hedin, 1895; Wu and Morris; 1998 and Gad, 2010). The kidney plays a major role in endogenous L-Arg synthesis (Peters et al., 1999; Osowska et al., 2004), where L-Arg is formed from L-citrulline produced by enterocytes (Dhanakoti et al., 1990). The liver is also capable of synthesizing certain amounts of L-Arg (Watford, 1991).

L-Arg is the only physiologically significant substrate for the biosynthesis of nitric oxide (NO) (Hecker et al., 1990). NO generated enzymatically from L-Arg by nitric oxide synthase (NOS) (Wood and Garthwaite, 1994). NO is produced by all tissues of the body and plays important roles in a broad range of physiological processes including cardiovascular homoeostasis, neurotransmission, vasorelaxation, macrophage cytotoxicity and immunity (Nahrevanian, 2009).

The discovery of NO as a neurotransmitter in the brain raised the issue of its role in the function of the central nervous system (CNS) (Garthwaite et al., 1988, Knowles et al., 1989; Snyder and Bredt, 1991). The release of NO strictly bound with the stimulation of N-methyl-D-aspartate (NMDA), a subtype of excitatory amino acid receptor, suggested an important role in psychomotor behavior (Wolf, 1998).

Several studies in recent years have investigated the versatile multiplex action of NO Using the nonselective NOS inhibitor $\mathrm{L}_{-} \mathrm{N}^{\mathrm{G}}$-nitro-L-arginine methyl ester (L-NAME) which exhibit antidepressant-like properties in the forced swimming test (Harkin et al., 1999). Several human and experimental animal studies have indicated that NO could be involved in the modulation of depressive behaviors (Peng et al., 2012).

In an attempt to understand the role of the NO in the modulation of depressive behaviors in rats, the present study aimed to investigate the effects of L-Arg on modulation of depressive behaviors in LPS-treated rats using open field test.

\section{MATERIALS AND METHODS}

\section{Animals}

Adult male albino rats were originally obtained from animal house, Faculty of Medicine, Assiut University, Assiut, Egypt, and were maintained in the Animal Care Facility at the Faculty of Veterinary Medicine, South Valley University. The animals were housed in cages $(55 \times 40 \times 20 \mathrm{~cm})$, under standard laboratory conditions $\left(22^{\circ} \mathrm{C}\right.$ temperature, 60 $\pm 5 \%$ humidity, in a $12 \mathrm{~h} \mathrm{light/dark} \mathrm{cycle),} \mathrm{with} \mathrm{food}$ and water ad libitum. Environmental factors (such as cage type and size, colony size, bedding, and environmental enrichment) were standardized between cages. They were kept for two weeks under this condition to adapt the laboratory conditions before the start of the experiment.

\section{Drugs and chemicals}

LPS (from Escherichia coli 0111:B4) and L-Arg were purchased from Sigma chemical company (Aldrich, USA). All drugs were dissolved in saline $0.9 \% \mathrm{NaCl}$. and administered i.p. in a volume of 0.1 $\mathrm{ml} / 100 \mathrm{~g}$ body weight (b.wt). Drugs were administered three hours prior to testing with the exception of L-Arg which, was administered 7 days prior to testing day.

\section{Experimental Design}

The experiment was carried out on twenty adult male albino rats (200-250 g) distributed in 4 groups of 5 animals each treated intraperitoneally as follows:

Group I (Control): saline solution $0.1 \mathrm{ml} / 100 \mathrm{~g}$ b.wt. Group II (LPS): LPS $1 \mathrm{mg} / \mathrm{kg}$ b.wt.

Group III (L-arginine): rats pretreated with L-Arg (10 mg/kg b.wt) for 7 days before saline injection.

Group IV (LPS+L-arginine): LPS-treated rats pretreated with L-Arg (10 mg/kg b.wt) for 7 days before LPS injection.

\section{Behavioral studies}

Measurement of locomotor activity was performed as previously described (Prut and Belzung, 2003; Araki et al., 2015). Briefly, Locomotor and behavioral activity were assessed using an infrared LE8811 Actimeter system (Panlab, Barcelona, Spain). The apparatus consisted of a $45 \mathrm{~cm}$ (width) $\mathrm{x}$ $45 \mathrm{~cm}$ (depth) arena of black plexiglass enclosed with four clear acrylic walls (35 cm in height) (Fig. 1). A square frame mounted outside of the arena created a $16 \times 16$ grid of intersecting infrared beams used to track the horizontal movement of each mouse in real-time. A second frame placed above the lower frame was used to track the vertical movement of each rat, set to detect hind-leg rearing. Locomotor measures were recorded using ActiTrack software (Panlab), which uses infrared beam data to calculate parameters such as overall locomotor activity (total number of beam breaks), distance traveled, and number of rears. The recorded data are easily exported in a format compatible with the Excel program for Windows, through a SeDaCom electronic software.

In the $8^{\text {th }}$ day, three hours after injection of the saline/LPS, testing was conducted during the light phase between 07:30 $\mathrm{h}$ and 12:30 $\mathrm{h}$ for all rats. Rats were brought into the testing room in their home cage a half hour prior to testing. Each rat was then placed in the corner of the arena and allowed to freely explore it for $5 \mathrm{~min}$. During testing, the lighting of the arena was $100 \mathrm{~lx}$ so as not to inhibit normal exploratory behaviour. At the end of testing, the rat was removed and returned to its home cage and the surface and walls of the arena were wiped clean with $30 \%$ isopropanol. 


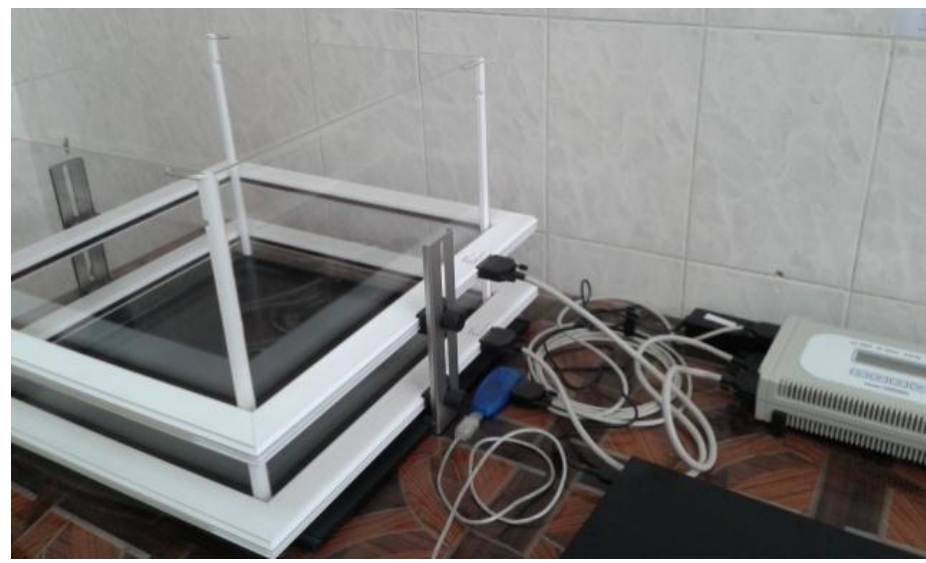

Fig. 1: Infrared LE8811 Actimeter (Panlab) apparatus for motor activity tracking in rats. Lower frame is used to track horizontal movements, while the upper frame tracks vertical movements (rearing).

\section{Statistics}

Statistical analysis was carried out using the Origin program for Windows version 6.0 for IBM and compatible computers. Statistical comparisons were made by student $t$ test. The obtained data were expressed as mean \pm standard error. P-values less than 0.05 were considered statistically significant and P-values less than 0.001 were considered statistically highly significant.

\section{RESULTS}

The effects of L-Arg pretreatment on the spontaneous total activity (total motor activity) in the LPS-treated rats

The treatment with LPS in a dose of $1 \mathrm{mg} / \mathrm{kg} \mathrm{b}$.wt did not significantly influenced the spontaneous total activity (216.60 \pm 127.86$)$, compared to the control (saline) group (348.00 \pm 199.30$)$ in a novel open-field test (Fig. 2).

Intraperitoneal administration of L-Arg $10 \mathrm{mg} / \mathrm{kg}$ b.wt was associated with an increase of the total motor activity (524.20 \pm 64.08$)$, but statistically not significant, compared to the group treated with saline $(348.00 \pm 199.30)$, in this behavioral experimental model in rats (Fig. 2).

The administration of L-Arg was associated with an important $(\mathrm{p}<0.001)$ increase of rat spontaneous total activity (524.20 \pm 64.08$)$, compared to LPS+Larginine group $(105.20 \pm 44.36)$ in this experimental behavioral model in rats (Fig. 2).

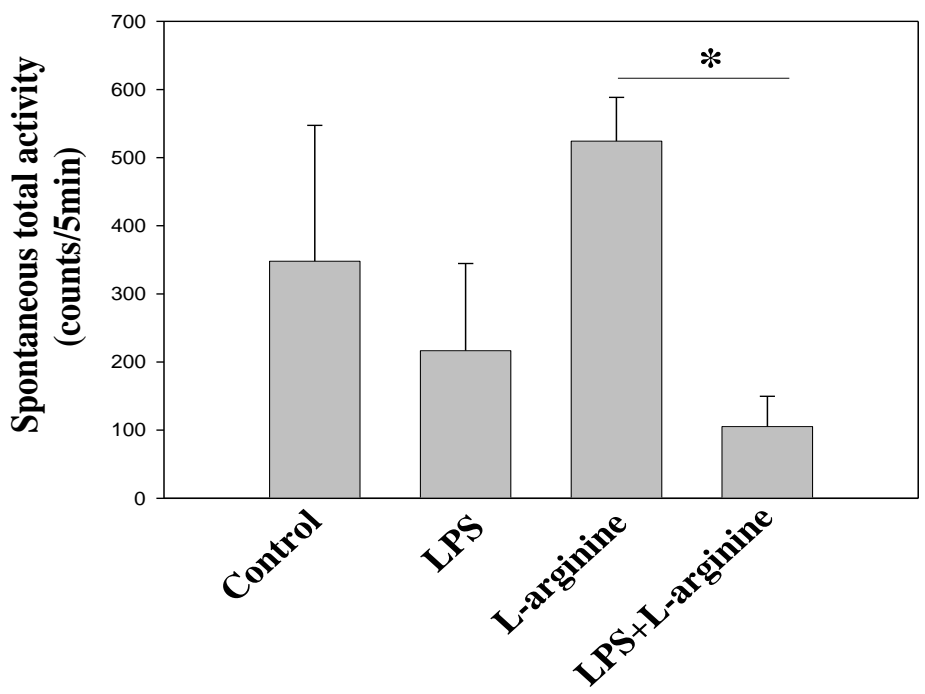

Fig. 2: Spontaneous total activity of rats in a novel cage environment. Data shown represent the mean $( \pm$ SEM) infrared beam breaks by control and treated rats 3 hours after saline/LPS injection ( $\mathrm{n}=5$ rats per group). *, p < 0.001; L-arginine vs LPS+L-arginine. 
The effects of $L$-Arg pretreatment on the number of horizontal movements (locomotor activity) in the LPS-treated rats

The use of LPS did not notably modify the number of horizontal movements (locomotor activity) (200.40 \pm 118.06$)$ compared to the saline group

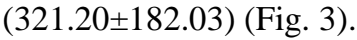

Also, the use of L-Arg did not notably modify the number of horizontal movements (locomotor activity) (492.80 \pm 60.93$)$ compared to the saline group (321.20 \pm 182.03 ) (Fig. 3).

The administration of L-Arg was associated with an important $(\mathrm{p}<0.001)$ increase of rat horizontal

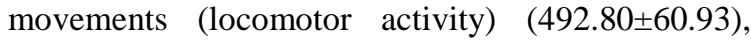
compared to LPS+L-arginine group $(98.60 \pm 42)$ in this experimental behavioral model in rats (Fig. 3).

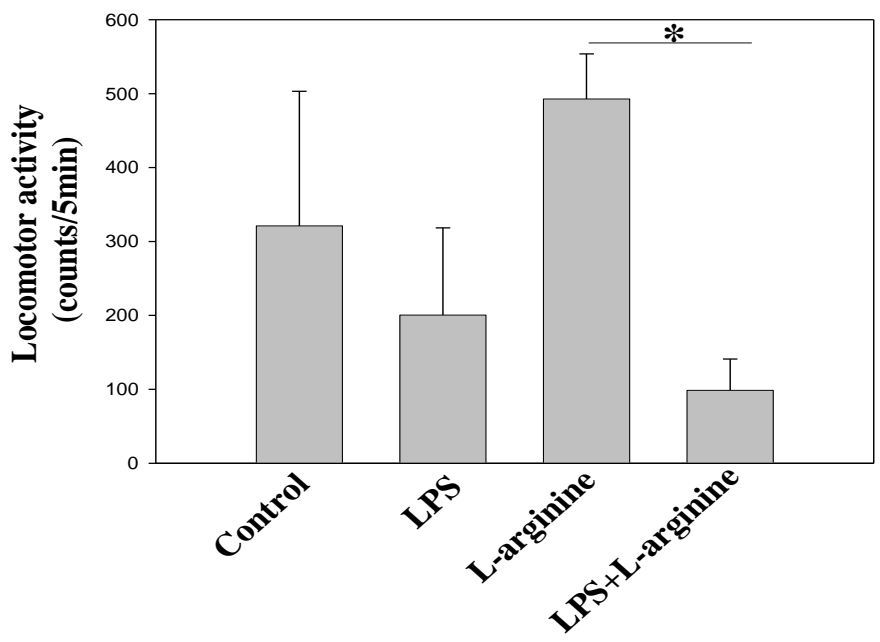

Fig. 3: Horizontal movements (locomotor activity) of rats in a novel cage environment. Data shown represent the mean $( \pm$ SEM) infrared beam breaks by control and treated rats 3 hours after saline/LPS injection $(n=$ 5 rats per group). *, $\mathrm{p}<0.001 ; \mathrm{L}$-arginine vs LPS $+\mathrm{L}$-arginine.

The effects of L-Arg pretreatment on the number of stereotype movements in the LPS-treated rats

Regarding the number of stereotype movements, no considerable variations were observed between LPS

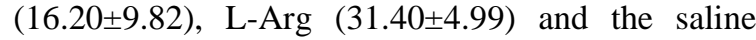
group $(26.80 \pm 17.46)$ in this experimental behavioral model in rats (Fig. 4).
The treatment with L-Arg in LPS-treated rats (LPS+L-arginine group) was associated with a statistically significant $(\mathrm{p}<0.01)$ decrease of the stereotype movements $(6.60 \pm 1.97)$, comparing with the L-arginine group (31.40 \pm 4.99$)$, during the session of experimentation (Fig. 4).

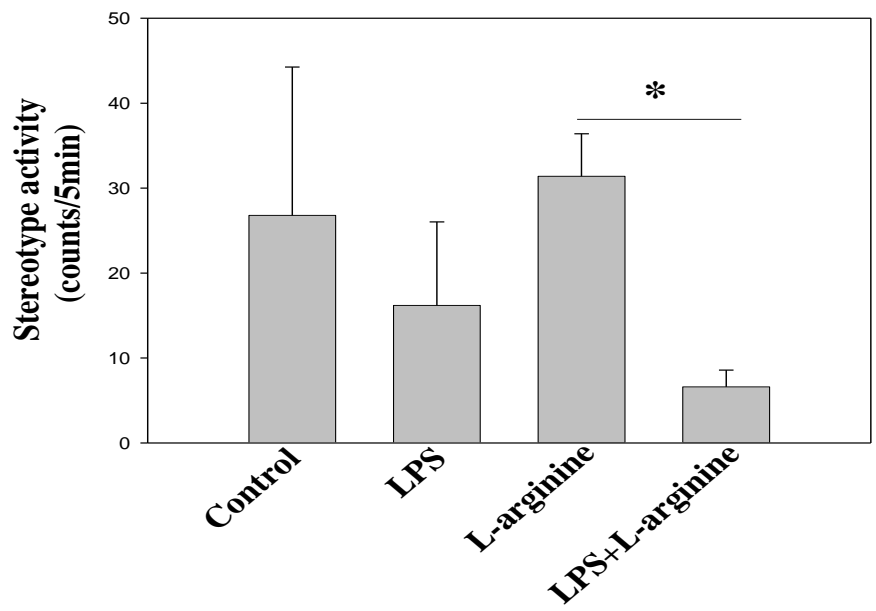

Fig. 4: Stereotype activity of rats in a novel cage environment. Data shown represent the mean ( \pm SEM) infrared beam breaks by control and treated rats 3 hours after saline/LPS injection $(\mathrm{n}=5$ rats per group). $*, \mathrm{p}<$ 0.01; L-arginine vs LPS+L-arginine. 
The effects of L-Arg pretreatment on the number of vertical movements (rearing) in the LPS-treated rats

Intraperitoneal injection of LPS did not determined considerable modifications in the number of vertical movements (rearing) $(10.00 \pm 7.89)$ comparing with the control group $(8.40 \pm 6.33)$, in the experiment
(Fig. 5).

The animals treated with L-Arg showed a significant $(\mathrm{p}<0.01)$ increase of the vertical movements (rearing) (9.80 \pm 2.01$)$, compared to LPS+L-arginine

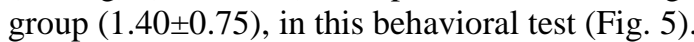

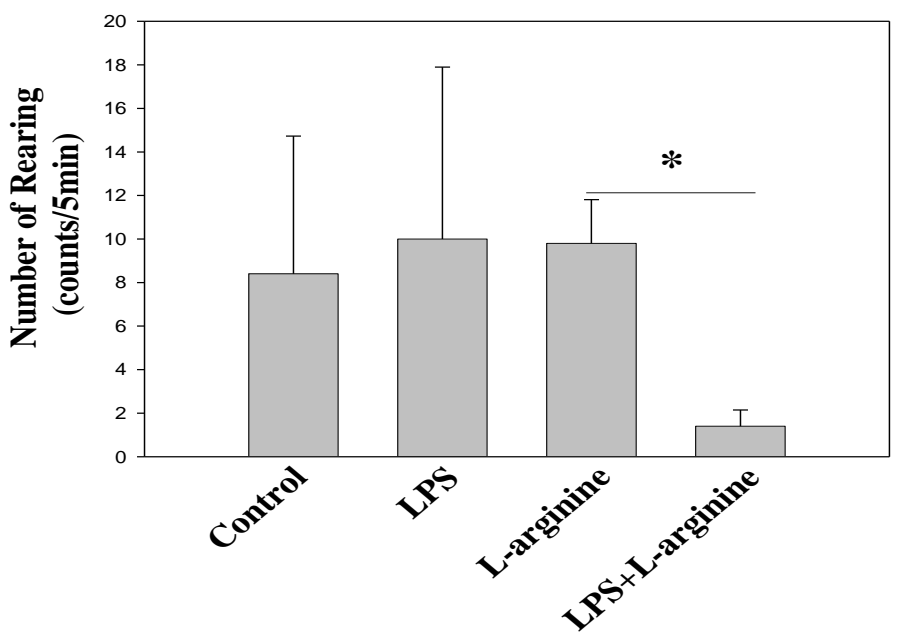

Fig. 5: Rearing activity of rats in a novel cage environment. Data shown represent the mean $( \pm$ SEM) infrared beam breaks by control and treated rats 3 hours after saline/LPS injection $(n=5$ rats per group). *, p < 0.01; L-arginine vs LPS+L-arginine.

The effects of L-Arg pretreatment on the total distance travelled in the LPS-treated rats

Intraperitoneal injection of LPS did not determine considerable modifications in the total distance travelled (302.32 \pm 194.88$)$ comparing with the control group (564.42 \pm 364.24$)$, in the experiment (Fig. 6).

The animals treated with L-Arg showed a significant $(\mathrm{p}<0.05)$ increase of total distance travelled (897.74 \pm 156.46$)$, compared to LPS group $(302.32 \pm 194.88)$, in this behavioral test (Fig. 6).

The animals treated with L-Arg in LPS-treated rats (LPS+L-arginine group) showed a significant $(p<0.01)$ diminution of the total distance travelled (128.46 \pm 73.50$)$, compared to L-arginine group (897.74 \pm 156.46$)$, in this behavioral test (Fig. 6).

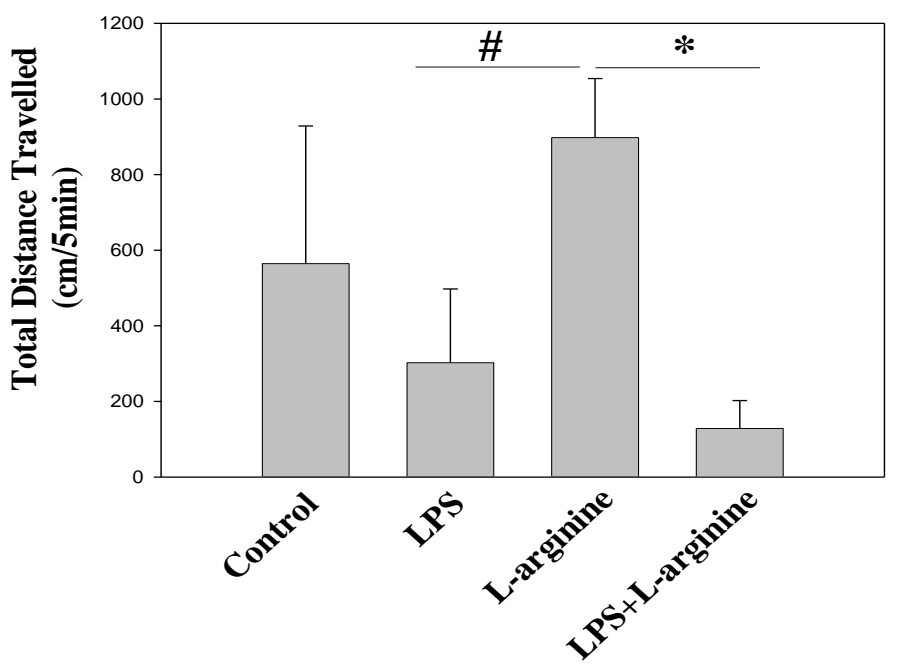

Fig. 6: Total distance travelled $(\mathrm{cm})$ by rats in a novel cage environment. Data shown represent the mean $( \pm$ SEM) infrared beam breaks by control and treated rats 3 hours after saline/LPS injection $(n=5$ rats per group). *, p < 0.01; L-arginine vs LPS+L-arginine. \#, p < 0.05; L-arginine vs LPS. 
The effects of L-Arg pretreatment on the mean velocity/Speed in the LPS-treated rats

Intraperitoneal injection of LPS did not determine considerable modifications in the mean velocity/Speed $(1.00 \pm 0.65)$ comparing with the control group (1.88 \pm 1.20$)$, in the experiment (Fig. 7).

The animals treated with L-Arg showed a significant $(\mathrm{p}<0.05)$ increase of the mean velocity/Speed
(2.98 \pm 0.53$)$, compared to LPS group $(1.00 \pm 0.65)$, in this behavioral test (Fig. 7).

The animals treated with L-Arg in LPS-treated rats (LPS+L-arginine group) showed a significant $(\mathrm{p}<0.01)$ decrease of mean velocity/Speed (0.42 \pm 0.25$)$, compared to L-arginine group $(2.98 \pm 0.53)$, in this behavioral test (Fig. 7).

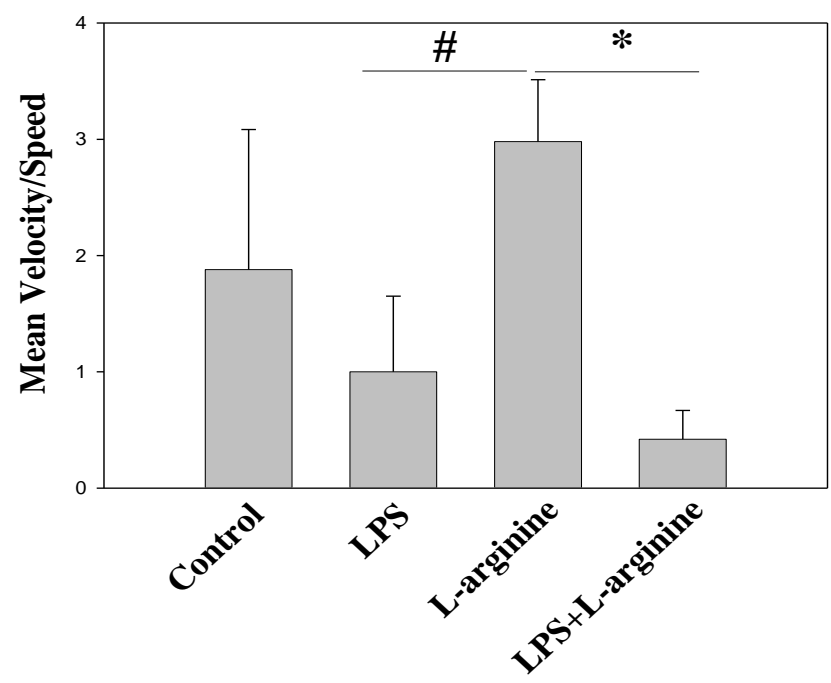

Fig. 7: Mean velocity/Speed of rats in a novel cage environment. Data shown represent the mean $( \pm$ SEM) infrared beam breaks by control and treated rats 3 hours after saline/LPS injection ( $\mathrm{n}=5$ rats per group). *, $\mathrm{p}<0.01 ;$ L-arginine vs LPS+L-arginine. \#, $\mathrm{p}<0.05$; L-arginine vs LPS.

\section{DISCUSSION}

Using an automated open field or an actimeter test, we estimated the spontaneous cage "motor" activity in rats (individual)by recording the horizontal and vertical activity (lower and upper photobeam breaks or counts, respectively), number of stereotypical movements, in a single-session of testing (Kas et al., 2008; Lynch et al., 2011).

The horizontal and vertical activities indirectly signify the animal state of fear and anxiety of the new environment, in which it was placed (Hart et al., 2010). On the other hand, the stereotype movements suggest the self-maintenance of animal personal hygiene (paw-licking activity, hair combing and nose cleaning, auto-grooming action) (Hart et al., 2010). The number of total movements represents an element that offer the information regarding the general rat behavior, during a definite interval of time, being a consistent tool for assessing the biological significance of obtained data (Lynch et al., 2011).

Previous studies indicate that intraperitoneal injection of LPS in rats induced robust sickness and depressive-like behavior in rats (Kirsten et al., 2015). In contrast, ourresults demonstrated that acute treatment with LPS produced slight sickness and depressant-like effects in the open field test in rats. These results diverge from previous studies may be due to the fact that LPS-induced sickness behavior and L-Arg antidepressant effects were dose dependant (Martin et al., 2013).

In addition, the present study seems to be the first to demonstrate that pretreatment with L-Arg alone produced non-significant increase in motor activities compared with rats treated with saline and/or LPS alone. Moreover, pretreatment with L-Arg in LPStreated rats accentuates endotoxin-induced sickness behavior in rats. These results were surprise for us, as we suspected that L-Arg has antidepressant effect. These accentuated effects of L-Arg are likely to occur through stimulation of inflammation and neural activation in the brain to secrete different types of cytokines (Dantzer et al., 1999).

\section{CONCLUSIONS}

The present study demonstrate that NO precursor L-Arg possesses significant depressant-like features that are LPS-dependent. Moreover, L-Arg may have a potential therapeutic value for treatment of anxiety symptoms in patients with sustained and systemic inflammation. 


\section{CONFLICTS OF INTEREST}

The author declares that there are no conflicts of interest regarding publication of this paper.

\section{ACKNOWLEDGEMENTS}

The author gratefully acknowledges all members and professors of the department of animal physiology, faculty of veterinary medicine, south valley university, Qena, Egypt, and of animal physiology department, faculty of veterinary medicine, Aswan university, Aswan, Egypt, for their constant encouragement and kind help. This work was supported by grant No. 2505 from the Science and Technology Development Fund (STDF), Egypt.

\section{REFERENCES}

Araki, R.; Hiraki, Y.; Nishida, S.; Kuramoto, N.; Matsumoto, K. and Yabe, T. (2015): Epigenetic regulation of dorsal raphe GABA associated with isolation-induced abnormal responses to social stimulation in mice. Neuropharmacology. 101: 1-12.

Aubert, A. (1999): Sickness and behaviour in animals: a motivational perspective. Neurosci Biobehav Rev. 23: 1029-1036.

Bluthe, R.M.; Walter, V.; Parnet, P.; Laye, S.; Lestage, J. and Verrier, D. (1994): Lipopolysaccharide induces sickness behaviour in rats by a vagal mediated mechanism. C. R. Acad. Sci. III. 317: 499503.

Dantzer, R.1.; Wollman, E.; Vitkovic, L. and Yirmiya, R. (1999): Cytokines and depression: fortuitous or causative association?. Mol. Psychiatry 4: 328-332.

Dantzer, R.; Bluthé, R.M.; Castanon-Faget, N.; Chauvet, N.; Capuron, L.; Goodall, G.; Kelley, K.W.; Konsman, J.P.; Layé, S.; Parnet, P. and Pousset, F. (2001): Cytokine effects on behavior. In Ader, R., Felten, D.L., Cohen, N. (eds), Psychoneuroimmunology. Vol $1,3^{\text {rd }}$ ed. New York, Academic Press, 703-727.

Dantzer, R.; O'Connor, J.C.; Freund, G.G.; Johnson, R.W. and Kelley, K.W. (2008): From inflammation to sickness and depression: when the immune system subjugates the brain. Nat. Rev. Neurosci. 9: 46-56.

Della Gioia, N. and Hannestad, J. (2010): A critical review of human endotoxin administration as an experimental paradigm of depression. Neurosci. Biobehav. Rev. 34: 130-143.

de Paiva, V.N.; Lima, S.N.; Fernandes, M.M.; Soncini, R.; Andrade, C.A. and Giusti-Paiva, A. (2010): Prostaglandins mediate depressive-like behaviour induced by endotoxin in mice. Behav brain Res. 215: 146-151.
Dhanakoti, S.N.; Brosnan, J.T.; Herzberg, G.R. and Brosnan, M.E. (1990): Renal arginine synthesis: studies in vitro and in vivo. Am. J. Physiol. 259: E437-42.

Frenois, F.; Moreau, M.; O'Connor, J.; Lawson, M.; Micon, C.; Lestage, J.; Kelley, K.W.; Dantzer, R. and Castanon, N. (2007). Lipopolysaccharide induces delayed FosB/Delta FosB immunostaining within the mouse extended amygdala, hippocampus and hypothalamus, that parallel the expression of depressive-like behavior. Psychoneuroendocrinology. 32: 516-531.

Gad, MZ. (2010): Anti-aging effects of 1-arginine. Journal of Advanced Research. 1: 169-177.

Garthwaite, G.; Charles, S.L. and Chess-Williams, R. (1988): Endothelium-derived relaxing factor release on activation of NMDA receptors suggests role as intercellular messenger in the brain. Nature 336: 385-388.

Haba, R.; Shintani, N.; Onaka, Y.; Wang, H.; Takenaga, R.; Hayata, A.; Baba, A. and Hashimoto, H. (2012): Lipopolysaccharide affects exploratory behaviors toward novel objects by impairing cognition and/or motivation in mice: possible role of activation of the central amygdala. Behav. Brain Res. 228: 423-431.

Harkin, AJ.; Bruce, KH.; Craft, B. and Paul, IA. (1999): Nitric oxide synthase inhibitors have antidepressant-like properties in mice. 1 . Acute treatments are active in the forced swim test. Eur. J. Pharmacol. 372: $207 \pm 213$.

Hart, B.L. (1988): Biological basis of the behavior of sick animals. Neurosci. Biobehav. Rev. 12: 123-137.

Hart, P.C.; Bergner, C.L.; Smolinsky, A.N.; Dufour, B.D.; Egan, R.J.; Laporte, J.L. and Kalueff, A.V. (2010): Experimental models of anxiety for drug discovery and brain research. Methods Mol. Biol. 602: 299-321.

Hecker, M.; Sessa, W.C.; Harris, H.J.; Anggård, E.E. and Vane, J.R. (1990): The metabolism of L-arginine and its significance for the biosynthesis of endothelium-derived relaxing factor: cultured endothelial cells recycle Lcitrulline to L-arginine. Proc. Natl. Acad. Sci. USA. 87: 8612-8616.

Hedin, S.G. (1895): One method to isolate the lysine, along with some remarks on the lysatinin. $\mathrm{Z}$. Physiol. Chem. 21: 297-305.

Kas, M.J.; de Mooij-van Malsen, A.J.; Olivier, B.; Spruijt, B.M. and van Ree, J.M. (2008): Differential genetic regulation of motor activity and anxiety-related behaviors in mice using an automated home cage task. Behav. Neurosci., 122: 769-776.

Kent, S.; Bluthe, R.M.; Kelley, K.W. and Dantzer, R. (1992): Sickness behavior as a new target for drug development. Trends Pharmacol. Sci. 13: 24-28 
Kirsten, T.B.; Lippi, L.L.; Bevilacqua, E. and Bernardi, M.M. (2013): LPS exposure increases maternal corticosterone levels, causes placental injury and increases IL-1 $\beta$ levels in adult rat offspring: relevance to autism. PLoS One. 2013; 8: e82244.

Kirsten, T.B.; Galvão, M.C.; Reis-Silva, T.M.; Queiroz-Hazarbassanov, N. and Bernardi, M.M. (2015): Zinc prevents sickness behavior induced by lipopolysaccharides after a stress challenge in rats. PLoS One. 10:e0120263.

Knowles, R.G.; Palacios, M.; Palmer, R.M. and Moncada, S. (1989): Formation of nitric oxide from L-arginine in central nervous system: A transduction mechanism for stimulation of the soluble guanylate cyclase. Proc. Natl. Acad. Sci. USA 86: 5159-5162.

Larson, S.J. and Dunn, A.J. (2001): Behavioral effects of cytokines. Brain Behav. Immun. 15: 371-387.

Lynch, J.J.; 3rd, Castagné, V.; Moser, P.C. and Mittelstadt, S.W. (2011): Comparison of methods for the assessment of locomotor activity in rodent safety pharmacology studies. J. Pharmacol. Toxicol. Methods, 64: 74-80.

Martin, S.A.; Pence, B.D.; Greene, R.M.; Johnson, S.J.; Dantzer, R.; Kelley, K.W. and Woods, J.A. (2013): Effects of voluntary wheel running on LPS-induced sickness behavior in aged mice. Brain Behav. Immun. 29: 113123.

Miyake, K. (2003): Innate recognition of lipopolysaccharide by CD14 and toll-like receptor 4-MD-2: unique roles for MD-2. Int. Immunopharmacol. 3: 119-128.

Nahrevanian, $H$. (2009): Involvement of nitric oxide and its up/down stream molecules in the immunity against parasitic. Braz. J. Infect. Dis. 13: 440-448.

Osowska, S.; Moinard, C.; Neveux, N.; Loï, C. and Cynober, L. (2004): Citrulline increases arginine pools and restores nitrogen balance after massive intestinal resection. Gut. 53: 1781-1786.

Peng, Y.L.; Liu, Y.N.; Liu, L.; Wang, X.; Jiang, C.L. and Wang, Y.X. (2012): Inducible nitric oxide synthase is involved in the modulation of depressive behaviors induced by unpredictable chronic mild stress. J. Neuroinflammation. 9: 75-87.

Peters, H.; Border, W.A. and Noble, N.A. (1999): From rats to man: A perspective on dietary 1arginine supplementation in human renal disease. Nephrol. Dial. Transplant. 14: 16401650 .

Prut, L. and Belzung, C. (2003): The open field as a paradigm to measure the effects of drugs on anxiety-like behaviors: a review. Eur. J. Pharmacol. 463: 3-33.

Snyder, S.H. and Bredt, D.S. (1991): Nitric oxide as a neuronal messenger, Trends Pharmacol. Sciences 12: 125-128.

Watford, M. (1991): The urea cycle: a twocompartment system. Essays Biochem. 26: 49-58.

Wolf, M.E. (1998): The role of excitatory amino acids in behavioral sensitization to psychomotor stimulants. Prog. Neurobiol. 54: 679-720.

Wood, J. and Garthwaite, J. (1994): Models of diffusional spread of nitric oxide: implications for neural nitric oxide signaling and its pharmacological properties. Neuropharmacol. 33: 1235-1244.

Wu, G. and Morris, S.M. Jr. (1998): Arginine metabolism: nitric oxide and beyond. Biochem. J. 336: 1-17.

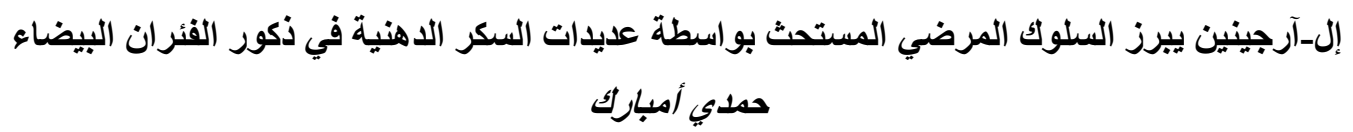

Email: h.embark@vet.svu.edu.eg; atutohm@yahoo.com Assiut University web-site: www.aun.edu.eg

سلوك المرض هو التغير ات السلوكية التي تحدث بعد وقت قصير من بداية العدوى، والصدمات، والعمليات الالتهابية. في الحيوانات، حقن عديدات

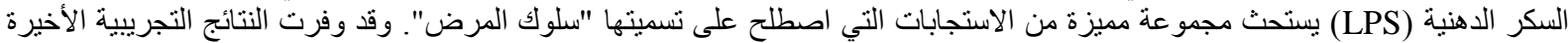

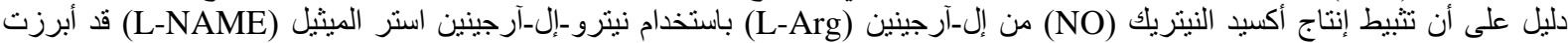

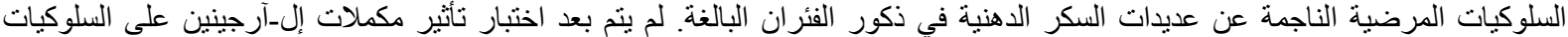

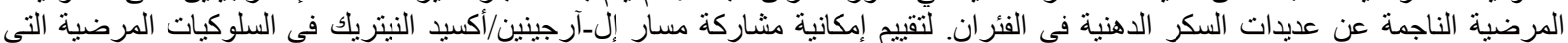

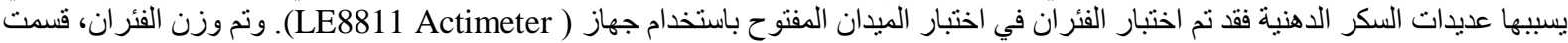

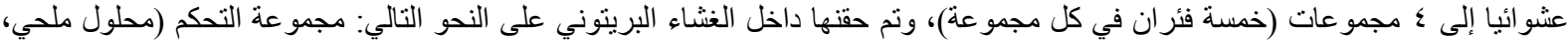

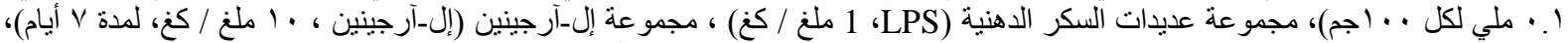

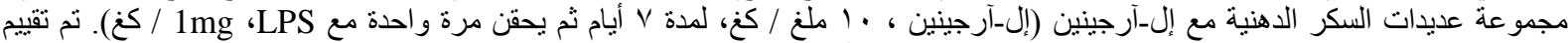

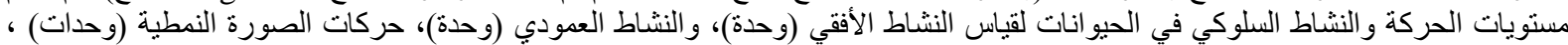

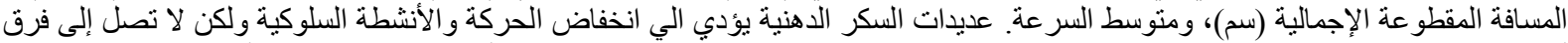

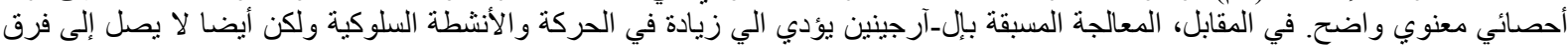

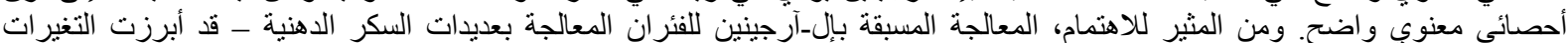

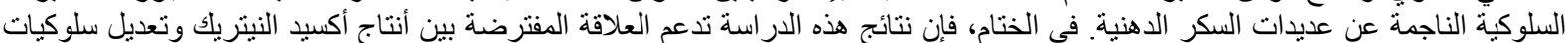

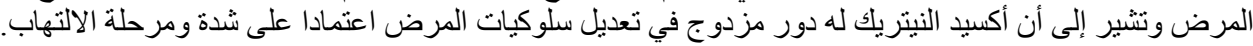

